\title{
Acerca de como las Mujeres Llegaron a ser Maestros (América Latina, 1870-1930)
}

\section{Silvia Cristina Yannoulas}

Faculdade Latino-Americana de Ciências Sociais/Universidade de Brasília (FLACSO/UnB)

Objetiva subsidiar teoricamente o debate sobre o processo de feminização da docência na escola de primeiro grau, na A mérica Latina, entre os anos de 1870 a 1930. Discute a relação entre afeminização da docência, a constituição e expansão dos sistemas educativos nacionais, e a elaboração e difusão de diversos tipos de identidade (especialmente identidades de género e identidade nacional). Sua organização está baseada em "palavras-chave" (key-words), vinculadas à problemática da feminização: diferença sexual, divisão sexual do trabalho, público e privado, Estado educador, educação feminina, profissão docente, formação docente efeminização da docência.

\section{Introducción}

La feminización de la profesión docente en la escuela primaria marco un importante hiato en la existência y representación simbólica de las mujeres. Existen otras profesiones que se feminizaron, pêro ninguna otra tuvo un valor simbólico y político similar: los nacientes Estados nacionales latinoamericanos depositaron en las manos de un cuerpo docente femenino la tarea de reproducir una nueva identidad, la nacionalidad.

Este texto, producto parcial de la investigación "La feminización de la docência en Brasil y Argentina (1870-1930)", tiene por finalidad aportar elementos teóricos a la Historia Social de la Educación, recuperando la 
dimensión genérica y latinoamaricana de la problemática educativa ${ }^{1}$. La reflexión sobre cómoy con qué concepciones se incorporaron las mujeres a la profesión docente, permitiria comprender mejor el significado de las diferencias y igualdad de hombres y mujeres en la organización de los sistemas nacionales.

\section{El problema}

Si se considera la profesión docente en el nivel primário dei sistema educativo y desde la perspectiva de género, se observa el hecho de que se ha transformado en una actividad predominantemente femenina. Y décimos transformado, porque desde sus orígenes (la figura dei pedagogo en la Grécia antigua) y hasta el siglo XIX, se trataba de una actividad exclusiva o predominantemente masculina.

Así, el desarrollo de los sistemas educativos nacionales también puede (y debe) ser observado como parte dei proceso histórico de división sexual dei trabajo. Llama la atención la escasa consideración hacia los aspectos de género de la profesión docente, apuntada en los estados dei arte sobre educación y mujer en América Latina (Rosenberg et alii, 1990; J. Corvalan, 1990), dado que la producción académica europea, canadiense y estadounidense senala insistentemente la importância dei sexo y dei género en la investigación sobre la escuela y la profesión docente, y dado que se estima que en más dei $85 \%$ de los docentes latinoamericanos de escuela primaria son mujeres ${ }^{2}$. Evidentemente, los estúdios sobre la condición femenina, los estúdios sobre educación y los estúdios sobre la división dei trabajo no se han beneficiado reciprocamente de los conocimientos acumulados en cada área.

\footnotetext{
${ }^{1}$ Los resultados finales de esta investigación, orientada por la Dra. Lourdes Maria Bandeira (UnB) y financiada por la CAPES y la Fundación Ford (Cono Sur), serán volcados en una tesis doctoral, a ser defendida en el marco dei Programa de Doctorado Conjunto FLACSO/UnB.

${ }^{2}$ En 1980, el $85 \%$ dei cuerpo docente dei nivel primário dei sistema educativo brasilero eran mujeres [Fucntc: VALDÊS, Teresa y GOMARIZ, Ernesto (ed ) (1993), Mulheres Latinoamericanos em Dados. Brasil, FLACSO/Iastituto de la Mujer (EspaBa), Santiago de Chile], En 1981 y para el caso argentino, el porcentaje es de 92\% [Fuente: BRASLAVSKY. Cecilia (Comp.) (1984), Mujery Educación. Desigualdades educativas en A mèrica Latina y el Caribe, UNESCO, Santiago de Chile],
} 
${ }^{\wedge}$ Cómo se produjo la feminización de la profesión docente en el nivel primário dei sistema educativo? iQué procesos políticos, económicos, culturales y sociales se encuentran ligados a esta transformación? ${ }^{\wedge}$ Cuáles eran las relaciones entre la feminización dei alumnado normalista (de escuela normal) y dei cuerpo docente por un lado, y la construcción de los sistemas educativos nacionales por el otro? A continuación, presentamos algunas de las categorias y dimensiones de análisis a ser consideradas para enfrentar estas preguntas.

\section{Diferencia sexual}

La sociedad capitalista industrial no puede existir más que imponiendo un postulado unisexual: los dos sexos están hechos para el mismo trabajo, perciben la misma realidad, y tienen las mismas necesidades. En los mercados capitalistas los seres humanos son, en principio, neutros económicos. Hombres y mujeres no podrían competir en el mismo mercado de trabajo si este no hubiese sido redefinido como una actividad conveniente a los seres humanos sin distinción de sexo(Ilich; 1982).

Desde las revoluciones burguesas y hasta hoy, el postulado de igualdad se consolido gradualmente, pêro conviviendo en conflicto con otro postulado: el de la existência de una identidad femenina $y$ una masculina, diferenciadas. La construcción discursiva de estas identidades se relaciono con el establecimiento de nuevas normas de conducta y espacios específicos para cada sexo. Particularmente a partir dei siglo XIX y en el mundo Occidental, tuvo lugar una preocupación focalizada por establecer identidades para cada sexo. Ello puede observarse, por ejemplo, a través de la lectura de diccionarios y enciclopédias, bajo los conceptos mujer, hombre, femenino, masculino, macho, hembra, etc; y también en las referencias efectuadas por científicos sociales (como Comte, Marx, Durkheim, Simmel, entre 
otros). Son estas identidades las que permitieron, en un contexto de igualdad formal, discriminar en la praxis a los seres humanos en virtud de su sexo.

A nuestro juicio, la identidad femenina se construyó discursivamente sobre la base de dos tipos de argumentación:

a) Argumentación ecológica ${ }^{3}$ : se refíere a la función reproductiva (biológica y social) que las mujeres deberían desempenar en relación ai hogar y a los hijos;

b) Argumentación esencialista: se refíere a las características atribuídas a Ias mujeres como parte de una esencia natural femenina (por ejemplo, la debilidad, la afectividad, la irracionalidad, la dependência, entre otras).

Estas argumentaciones constituyeron una nueva matriz de significado, la noción de identidad femenina dei siglo XIX, colocando como ideal femenino por excelência la maternidad, y como espacio femenino privilegiado el privado. Maternidad y espacio privado que fueron redefinidos en un contexto histórico marcado por Ia aparición de los Estados nacionales, por la industrialización y la urbanización. Los políticos, los demógrafos, los sociólogos, los pedagogos, los economistas, los sindicalistas, los legisladores y las feministas esencialistas y reformistas construyeron diversos discursos que colocaron a la madre como la principal responsable dei bienestar y la educación de sus hijos (futuros ciudadanos). La família nuclear constituyó un nuevo modelo de família, adaptado a las necesidades de la urbe, dei Estado nacional y a la nueva concepción de maternidad. A partir de esta identidad femenina se legitimo la discriminación de las mujeres en el mercado de trabajo, aún afirmando paralelamente la igualdad de los indivíduos.

Paralelamente, la identidad masculina se construyó discursivamente sobre la base de otras dos argumentaciones:

\footnotetext{
${ }^{1}$ La palabra "ecologia" deriva dei griego ôikos, que quiere decir casa. En este sentido. ]a argumentación ecológica se refíere a la posición que debería ocupar la mujer en relación ai espacio doméstico y privado.
} 
a) Argumentación política ${ }^{4}$ : se refiere la función productiva y pública que el hombre debería desempenar en relación a la sociedad;

b) Argumentación esencialista: se refiere a las características atribuídas a los hombres como esencia natural (por ejemplo: la fuerza física, la agresividad, la racionalidad, la independência, entre otras).

Si aplicamos estos conceptos de igualdad y de identidad ai proceso de feminización de la docência en América Latina, podriamos decir que la docência en la escuela primaria fue considerada una actividad a desarrollar por los seres humanos sin distinción de sexo, pêro según el argumento naturalista de la identidad femenina, las mujeres podrían realizar mejor esta tarea. A su vez, la escasa remuneración otorgada a las profesionales de la ensenanza se justificaba en gran medida por el argumento ecológico de la identidad femenina: las mujeres solo brindan a la família un salário complementario, siendo hijas o esposas de un hogar donde un jefe de família (padre o esposo) desempena el papel sustentador.

\section{División sexual dei trabajo}

La división sexual dei trabajo es una categoria utilizada por las Ciências Sociales para indicar que en cada sociedad, hombres y mujeres realizan tareas diferentes. Si bien el género ${ }^{5}$ ha sido definido de forma variada a lo largo de la historia y en diferentes culturas, los estúdios históricos, antropológicos y sociológicos han demostrado que el sexo $^{6}$ constituye

\footnotetext{
${ }^{4}$ La palabra "política" deriva dei griego polis, y se opone a óikos. En este sentido, la argumentación política se refiere a la posición que debería ocupar el hombre en relación ai espacio público.

* La palabra "género" proviene dei latín genus. En su acepción gramatical, se refiere ai accidente (desinência diferencial) que sirve para indicar el sexo de las personas o de los animales, y el que se le atríbuye a las cosas (o bien para indicar que no se les atríbuye ninguno a traves de la forma neutra de algunas lenguas) (Corominas; 1954 yLarousse; 1867). Según Scott (1983-1988) la categoria género fue tomada en préstamo de la Gramática por las Ciências Sociales (en parucular por la Antropologia) para indicar ladistinción entre atributos culturales historicamente otorgados a hombres y mujeres (género), y la dimensión biológica de los seres humanos (sexo).

${ }^{6}$ La palabra "sexo" proviene dei latín sexus, donde la raiz sec- indica división (el verbo secare significa separar, dividir). Gramaticalmente, la palabra sexus se acompafta de vihlis (masculino) o de muliebris (femenino). Así, la palabra sexo se refiere a la condición orgânica que distingue ai macho de la hembra.
} 
uno de los critérios básicos, estructurales y constantes de distribución de las potencialidades humanas de cada cultura.

La industrialización y la urbanización occidental dei siglo XIX produjeron una nueva división sexual dei trabajo, otorgando nuevos significados a los conceptos de trabajo, público y privado, y femenino y masculino; y estableciendo separadamente la esfera dei trabajo doméstico/ reproductivo/gratuito/privado/femenino, y la esfera dei trabajo fuera de la casa/productivo/remunerado/público/masculino (Hausen; 1976). Comenzó a reconocerse bajo el concepto de trabajo solo a las actividades productivas, siendo excluída cualquier actividad de reproducción. Privado pasó a designar todo lo relativo ai espacio intra-muros de la casa, residência de la família nuclear. Se asignó a los hombres la tarea de "trabajar" y a las mujeres la de cuidar dei hogar y de los hijos. Los discursos de los políticos, los demógrafos, los pedagogos, los economistas, los legisladores, los sindicalistas, algunas feministas y posteriormente de la psicologia contribuyeron a montar estos nuevos significados y sus relaciones.

El contenido de la legislación laboral sancionada en América Latina hacia finales dei siglo XIX y comienzos dei siglo XX expresa ideas específicas sobre las mujeres, sus características espirituales, emocionales y físicas, y una asignación de roles particulares en el seno de la família. El trabajo femenino remunerado (en particular, aquel que se desempefíaba en las fábricas) era considerado danino para la salud biológico-reproductiva de las mujeres (concepción que se comprende a la luz de las condiciones de trabajo que las mujeres sufrían en las fábricas y en el trabajo domiciliar a destajo). Era también considerado danino para la constitución familiar y la reproducción social (y por ende, para la nación), dado que la família dependia de las mujeres tanto en su integración como en su "salud moral". Este tipo de concepciones dominó todo el espectro político latinoamericano (incluyendo a los socialistas y a algunas feministas!).

Sintetizando: se podría decir que Ia participación femenina en el mercado de trabajo formal fue permitida (como desgracia inevitable), pêro no promovida (aunque si controlada), dado que la principal función de las 
mujeres era la maternidad y la preservación dei núcleo familiar. Sin embargo, hubo una excepción: en America Latina el rol docente fue fomentado y no solo permitido o tolerado. Adernas, la participación femenina en el mercado de trabajo en algunas ocasiones fue promovida apelando ai discurso de la "emergência" (en caso de guerras, por parte dei gobiemo), ai discurso dei "neutro económico" (leyes de la oferta y la demanda, por parte de los capitalistas), y ai de la "emancipación femenina" (particularmente de las feministas socialistas). Se trata de discursos alternativos, con los cuales el capitalismo convive y manipula. De esta forma, en ciclos de crisis dei mercado de trabajo por escasez de mano de obra, las mujeres son llamadas a participar; mientras que en ciclos de crisis dei mercado de trabajo por abundância de mano de obra, las mujeres son excluídas dei mercado de trabajo.

\section{Público y privado}

Según Arendt (1958), el espacio público estaba originalmente constituído por los hombres que "se aparecían" frente a los otros, y se hablaban en un interesse o mundo común. Entre los griegos, el espacio público equivalia a Ia polis, mientras que el espacio privado equivalia a la casa. En el espacio público, cada qui ${ }^{l}$ se presentaba ante los otros, sin fundirse en el anonimato colectivo. El espacio público era el espacio plural y heterogéneo por excelência, donde lo único igual estaba constituído por el derecho a la palabra y a la acción.

La capacidad humana de organización política se oponía directamente a esa asociación natural cuyo centro estaba constituído por la casa (ôikia). El espacio privado (que era el espacio de las mujeres y de los esclavos) se encontraba en la esfera de las necesidades, de todo aquello relacionado

\footnotetext{
${ }^{1}$ Qui es una palabra latina, que significa quien. En este contexto, alude a la individualidad de la persona, a sus características y particularidades, que la destacan de otras personas.
} 
con el mantenimiento y la reproducción de la vida. La ley de lo privado era la desigualdad universal, y el espacio privado era el reino de la necesidad.

La esfera social, que no es privada ni es pública, es un fenómeno relativamente reciente, cuyo origen coincidió con el surgimiento de la modernidad europea y cuya forma política es el Estado-Nación. Lo social es la forma de colectividad humana en la cual el qui pierde su poder de aparecer, de hablar y actuar, en la confusión anónima. En la confusión anónima ya no existe lo público y lo privado (la sociedad de masas es su ápice). En lo social todo se exhibe pêro nadie aparece. Todo se dice pêro nadie habla. La aparición de lo social implico la perdida de la pluralidad pública y de la desigualdad privada, a partir de una ley de igitaldad entendida como homogenezación.

La esfera social espera de cada uno de sus miembros un cierto tipo de comportamiento, imponiendo innúmeras y variadas regias, todas ellas tendientes a "normalizar" la conducta de sus miembros, a destruiria acción espontânea o la palabra inusitada. La aparición dei espacio social en el mundo occidental moderno implico la reducción de lo público en benefício de lo social, y paralelamente la esfera social se instituyó como espacio de mediación entre lo público y lo privado.

Estos conceptos de esfera pública, social y privada indican caminos interesantes para repensar la feminización de la docência latinoamericana en el nivel primário dei sistema educativo nacional. Con la aparición de un "cuerpo docente", cuya construcción fue, en America Latina, paralela a la incorporación de las mujeres, la tarea docente pasó a ser pautada y controlada cada vez más; y los profesionales especializados pasaron a ser intercambiables. Por tanto, se ubican en la esfera social, donde los qui no hablan (por si mismos, ya que no producen o critican el conocimiento a ser transmitido) ni aparecen (en el sentido de que los docentes carecen de singularidades ai ser intercambiables). Si la tarea docente se convirtió en extensión de las actividades domésticas, si los alumnos (uniformados) dejaron de tener personalidad propia para pasar a ser pensados como equivalentes, la escuela primaria pública se encuentra en la esfera social. 


\section{Estado educador}

El concepto moderno de nación se asocia a fenómenos cohesivos, que intentan integrar las múltiples particularidades regionales (Rivas; 1986). El elemento original dei Estado nacional moderno es el de vincular regiones dispares y dispersas simbolicamente (a través de la creación de una comunidad imaginaria, según el concepto de Anderson; 1977) y materialmente (através de la creación dei mercado interno y sus relaciones con el mercado internacional).

Para Calderon (1988), la modernidadfue en Europa el resultado de un largo proceso de racionalización y secularización, mientras que en América Latina fue producto de una introducción "forzada" por via de la colonización en primera instancia, y de las elites criollas republicanas dei siglo XIX en segunda instancia. En América Latina, la organización de los Estados nacionales estuvo determinada por la re-definición de las relaciones económicas internacionales, a través de la constitución dei sistema de economía-mundo. La universalización dei capitalismo requeria de la formación de Estados nacionales latinoamericanos, que renovasen los pactos coloniales bajo nuevos esquemas (Donghi; 1986).

En Europa occidental, el Estado nacional se constituyó como expresión y resultado dei desarrollo de la sociedad civil. Su sistema de dominación se basó en el consentimiento de las masas, en tanto estas creían ejercitar su auto-gobierno en un Estado que las representaba. Este tipo de Estado nacional burguês se diferencia radicalmente de los Estados nacionales oligárquicos de América Latina (Carmagnani; 1984). Las naciones latinoamericanas se originaron y consolidaron a través de y por el Estado, y no a la inversa como ocurrió en Europa occidental. El Estado nacional latinoamericano no se constituyó en representante de la sociedad civil, sino en el encargado de conformaria.

Para integrar una nación en América Latina, era requisito superar el aislamiento, la miséria, y dotar ai país de instituciones y legjslación modernas. A juicio de los políticos de la época, se requeria de políticas educativas a mediano 
y largo plazo, con inversiones significativas para construir edifícios, formar un cuerpo docente homogéneo, sancionar legislaciones en matéria educativa y cultural, entre otras cosas.

A nuestro juicio, la creación de los sistemas educativos nacionales latinoamericanos obedeció ai objetivo de construir identidades nacionales, y por tanto, a Ia intención de otorgar un mínimo de homogeneidad a la población a partir de la creación de las nuevas comunidades imaginarias. ${ }^{8}$ La construcción de sub-identidades (raciales, sexuales, étnicas, religiosas) se acelero ai mismo ritmo en que el principio de igualdad de los ciudadanos de una misma nación ganó terreno. Los constructores de las naciones fueron, paralelamente, constructores de razas, sexos, etnias, clases (Williams; 1989). Es un doble movimiento, que iguala a los seres humanos a partir de la construcción de la identidad nacional, y asimismo los diferencia, a través de la creación de subidentidades (las mujeres, los indios, los negros, los trabajadores, entre otras), todas ellas englobadas en la identidad nacional. En el reino de la igualdad, son las sub-identidades las que permiten discriminar a los indivíduos.

La escuela pública se tomo la encargada legal y legítima de transmitir la nueva identidad nacional, a través de tradiciones inventadas (la historia, el folklore, los rituales, etc.) (Hobsbawn y Ranger; 198 3), inventadas íuera de la escuela pêro re-creadas y re-producidas por ella. Y, paralelamente, el sistema educativo nacional se torno en uno de los mecanismos privilegiados de clasificación de la población (heterogénea) en sub-identidades (sea por su exclusión total o por su exclusión parcial, es decir, el no acceso de determinados grupos a ciertos niveles y modalidades dei sistema educativo).

En América Latina, la educación pública fúe pensada para romper con el pasado colonial y construir a la nación y ai ciudadano (Zea; 1949). En este

\footnotetext{
${ }^{8}$ El nuevo modelo agro-exportador no precisaba de calificación de la mano de obra para su implementación. Si precisaba de profesionales y burocratas, que fueron formados en los niveles secundário y superior dei sistema educativo. Por tanto, la expansión dei nivel primário dei sistema educativo en América Latina se vinculo prioritariamente con una función política: transmitir, socializar y disciplinar a la población según los nuevos valores nacionales. Se estableeió una nueva paradoja. la función politica dei nivel primário dei sistema educativo, sistema ubicado discurstvamentc en el espacio público, fue desempenada por mujeres (que en el mismo discurso debian permanecer fuera de la esfera pública). Esta paradoja fue resuelta por la separación entre produeción y transmisión de saberes: las maestras transmitían pêro no producían los saberes.
} 
contexto, se necesitaba un número importante de maestros, que Uevaran a cabo esta "obra civilizadora" en todos los rincones dei país. En el discurso de la época, se asigna gran importância a la formación de un cuerpo docente, para la implementación dei proyecto educativo nacional. Para un provecto de tal envergadura no era suficiente la acción pedagógica de maestros aislados, que ensenaran a unos poços lo que ellos mismos sabían. Se necesitaba de un cuerpo de profesionales, que llevara a cabo simultaneamente la misma tarea civilizadora.

Es necesario, sin embargo, establecer algunas diferencias en lo que se refiere a la constitución dei Estado nacional en Brasil. La forma federativa y descentralizada que asumió el Estado nacional a partir de 1891 coloco serias limitaciones a su rol de Estado Educador. Sin embargo, podemos encontrar ciertos paralelismos con otras experiências latinoamericanas. En primer lugar, el proyecto pedagógico de envergadura nacional existió discursiva y materialmente: autores como Veríssimo (1890) representan el aspecto discursivo, mientras que el Pedagogium de Benjamin Constant representa su aspecto material. En segundo lugar, la Constitución de la República de 1891 delego en los estados (ex-provincias) la competência de legislar y proveer educación primaria. Es decir, la educación primaria pasó a ser matéria de las políticas públicas gubemamentales, aún cuando no fuese directamente ingerência dei Estado nacional.

\section{Educación femenina}

En el período que transcurre entre 1850 y 1930, la educación femenina y la mujer como educadora se instituyeron como objeto de reflexión políticopedagógica europea y americana. Si bien antes de 1870 se debatió sobre estas problemáticas, el alcance dei debate (en términos de cantidad y tipo de actores involucrados) no fue tan amplio ni tan intenso, y no se debatió sobre:

a) el concepto de educación femenina como preparación para la administración científica dei hogar y la salvaguarda de los jóvenes (futuros ciudadanos) de la nación; 
b) la mujer como trabajadora docente, funcionaria dei sistema educativo nacional (público);

c) la igualdad de los sexos y su coeducación.

La educación femenina previa se dirigia a las muchachas de clases privilegiadas (canto, danza, francês, etc.) y en aulas particulares o en aulas particulares y congregaciones religiosas. En algunos casos, fue implementada formación específica para que las mujeres de sectores desfavorecidos se desempenasen mejor como empleadas domésticas (en particular las acciones educativas fomentadas por las asociaciones de beneficência, escuelas de artes y ofícios).

En nuestro período de análisis, la preocupación específica por la educación de las mujeres se relacionaba basicamente con el nuevo concepto de maternidad (Badinter; 1980). La mayoría de los pensadores latinoamericanos de la época sostenían el siguiente principio políticopedagógico: la más importante función de los educadores es instruir a las mujeres, para que se conviertan en "verdaderas madres", y eduquen correctamente a sus hijos desde su más tierna infância. El concepto de maternidad fue de esta forma ampliado más allá de lo doméstico: tenía una función pública, formar a los nuevos ciudadanos, dentro de las expectativas dei Estado-Nación. Se pensaba que los avances educativos logrados por el Estado nacional estarían en peligro frente a "una ambiente hogareno retrasado".

Los cursos de economia doméstica se convirtieron en regia general en las escuelas para ninas y muchachas. Pretendían elevar la atención dei hogar y de los hijos ai nivel de una ciência. Se alentaba a las alumnas a ejercer más influencia en el manejo dei hogar. Se les ensenaba como organizar las tareas domésticas, como administrar los ingresos y los gastos, como ahorrar dinero, como pedir prestamos para necesidades especiales. Muchos programas comprendían cursos científicos sobre la crianza de los hijos y la higiene personal.

En cuanto a la mujer docente, el trabajo remunerado de la misma fue concebido como una ampliación de sus nuevas tareas en el hogar: la 
formación de las jóvenes generaciones. Se necesitaba un cuerpo docente, de bajo costo, que llevase a cabo la "gran cruzada pedagógica": baratas, dóciles y sin otras oportunidades laborales "decentes" y atractivas, las mujeres pasaron a ser consideradas "educadoras por excelência". La maestra tenía ventajas comparativas frente ai maestro, dado que para los políticos y pensadores de la época "las mujeres instruyen menos pêro educan más". Adernas, si la mujer había sido definida como la encargada de los ninos en el hogar, parecia razonable que continuase con su labor pedagógica en el âmbito escolar dei nivel primário.

\section{Profesión docente}

Se denomina profesión a toda actividad laboral o tipo de ocupación habitual que requiere de una preparación o califícación específica. En el caso de la profesión docente, la preparación específica se relaciona con la formación académica y la formación pedagógica, generalmente impartida por instituciones creadas a tal efecto (Debesse y Mialaret; 1978). La especificidad de la profesión docente se define sobre cuatro critérios diferentes:

a) El tipo de contrato que regula el ejercicio de su profesión. el docente es un profesional subalterno, ai cual se le asigna la tarea de transmitir saberes de diferente tipo (valores, saberes instrumentales, normas de conducta, etc).

b) La relacion con el conocimiento o formación académica: el docente es un profesional que domina ciertas áreas de conocimiento, a ser transmitidos. Capacitados fundamentalmente para transmitir, los docentes no fueron pensados como productores o críticos dei conocimiento que ellos mismos transmiten.

c) La relacion con la infância o formación pedagógica: el docente es un profesional que trabaja con la infância (y debe tener la capacidad y las metodologias específicas para ello). 
d) La relación simbólica dei docente con la sociedad: el docente se habria convertido en el "sacerdote" indiscutible dei saber legitimado.

El reclutamiento y formación dei personal adecuado constituyó una de las premisas fundamentales para la empresa de construcción de los sistemas educativos de alcance nacional en América Latina. La práctica de ensenar, que hasta ese momento se había realizado de manera mas o menos espontânea, requerirá por parte de aquellos que la desempenen la posesión de ciertas destrezas y habilidades, certificadas por un título de maestro. La constitución de un cuerpo docente o magistério homogéneo aseguraría un proceso relativamente unificado de inculcación cultural. El desempeno de la práctica pedagógica ya no quedo librada a la subjetividad de personas individuales (según maneras y hasta incluso formaciones previas desiguales), sino que presentó un carácter tipificado, pautado. Implico que aquellos que la realizasen, estuviesen provistos de un corpus de conocimiento específico y compartido. El requisito formativo posibilitaba intercambiar indivíduos (los maestros de escuela primaria), sin que sufriera alteraciones la función social desempenada (práctica pedagógica).

El cuerpo docente o magistério, como todo grupo social, tiene una doble existência. Por un lado, la existência material objetiva, que puede ser cuantificada según una serie de propiedades (sexo, edad, origen social, etc). Por otro lado, y en relación con esa existência material, el magistério puede ser analizado como representación cultural o matriz de significado (Feldfeber; 1990). Esta doble existência dei magistério, material y simbólica, tiene consecuencias en relación ai sexo y ai género: su existência material objetiva en cuanto a la composición dei alumnado normalista según el sexo; y las representaciones acerca dei magistério, que prescriben el deber ser dei docente en una forma genericamente discursiva.

La mayor parte de la literatura específica presenta la particularidad de considerar a la docência como una profesión asexuada. Se ha llegado ai extremo de afirmar que "los estúdios normalistas ayudan a los alumnos a desempefíar 
mejor sus roles de esposa y madre" (Rosemberg; 1990). Esta frase resulta ejemplar, en el sentido de revelar las paradojas de la lógica patriarcal que permanece aún en el reino de la igualdad, donde el Sujeto o el individuo siempre es enunciado en su forma gramatical masculina.

\section{Formación docente}

Hacia îinales dei siglo XVII surgió la preocupación por la formación docente en los estados territoriales dei âmbito germânico. Se inauguraron en diferentes ciudades y vinculados a diferentes tipos de instituciones (escuelas primarias, orfelinatos, etc.) los seminários de formación de maestros (Lehrerseminaren), basicamente a cargo de teólogos. Hacia mediados dei siglo XVHI surgió y se expandió en el contexto dei Império Austro-Húngaro la escuela normal (Normalschule), también a cargo de teólogos (Engelbrecht; 1984 y 0'Brien; 1970) ${ }^{9}$. Con la Revolución, se incorporo en Francia el modelo institucional de las escuelas normales (écoles normales), pêro en un contexto basicamente laico.

En los Estados Unidos de América, la escuela normal surge en la primera mitad dei siglo XIX, y crece paralelamente con la escuela primaria. Concomitantemente, entre 1820 y 1860 tuvo lugar la transición hacia la feminización (predominância relativa de mujeres) de la profesión docente (Apple; 1987). En América Latina, en la segunda mitad dei siglo XIX comenzaron a fundarse escuelas normales con el fin de expandir la educación popular (Weinberg; 1984). Sin embargo, poço sabemos aún acerca de la génesis de la incorporación de las mujeres tanto en las Escuelas Normales (como alumnas) como en las escuelas primarias (como docentes).

\footnotetext{
${ }^{9}$ En los libros contemporâneos sobre Historia de la Educación, generalmentc se identifica el origen de la escuela normal con la Francia pos-revolucionaria (y particularmente con la figura de Lakanal), sin reconocer sus antecedentes prusiano y austro-húngaro. Sin embargo, la primera vez que se utilizo la expresión escuela normal (Normalschule) fue en 1763, cuando el sacerdote católico Von Felbiger fundo en Sagan (ciudad que pertenecía a Prusia en es momento) una escuela modelo para la formación de maestros que ensefiasen lecto-escritura y cálculo. La primera institución de formación de maestras fue el curso normal (Normalkvrse) para sefioritas, fundado en 1783 en la ciudad de Múnster (Westfalia).
} 
El título docente se convirtió en garantia de competência más allá de las propiedades de los sujetos portadores. El título docente, en tanto credencial de competência cultural, confino a su portador un valor convencional, constante y garantizado juridicamente en relación con la cultura. Es precisamente la titulación la que instituyó ai grupo como realidad trascendente a los indivíduos, mediante una forma jurídica y valores dei grupo (Bourdieu; 1989), y la que permitió la intercambiabilidad de los profesionales. La concepción que dio origen ai cuerpo docente es el resultado de un proceso de re-definición dei campo de la circulacióny reproducción de saberes. Institucionalizar prácticas pedagógicas significo trazar limites precisos entre saberes socialmente válidos y no válidos, entre inculcadores legítimos e inculcadores no legítimos. Y también significo excluir de la escuela y de la formación de los maestros la producción de los saberes socialmente válidos.

\section{Feminización de la docência}

La bibliografia consultada nos permitiria postular dos tipos de feminización de la profesión docente, según la relación establecida entre la incorporación de mujeres ai cuerpo docente, la obligatoriedad escolar y la pre-existencia de um cuerpo docente masculino:

a) Proceso basicamente conflictivo: cuando la obligatoriedad escolar y Ia formación de un cuerpo docente masculino antecedieron ai proceso de feminización, y el conjunto de los actores masculinos involucrados se oponía firmemente ai ingreso de las mujeres a la actividad de ensenanza (implicando en contrapartida y en algunos países, acciones de movimientos feministas). En estos casos, el proceso de feminización de la docência tuvo lugar más tardiamente, y generalmente estuvo asociado a la salida de los hombres de sus puestos de trabajo a raiz de guerras.

b) Proceso sin conflictos: cuando la obligatoriedad escolar y la formación 
de un cuerpo docente tuvieron lugar paralelamente o incluso con posterioridad a la fundación de instituciones destinadas a la formación de personal, y los actores masculinos involucrados concordaban y apelaban ai ingreso de las mujeres en la actividad de ensefianza. En estos casos, el proceso de feminización de la docência se desarrolló más rapidamente.

Estos procesos de feminización sin conflictos difieren radicalmente de los procesos conílictivos en cuanto a la construcción discursiva, por parte dei Estado, de la profesión docente: las mujeres fueron llamadas a participar activamente en el proceso de consolidación de un sistema educativo nacional en aquellos países donde el peso de la tradición de un cuerpo docente masculino no existia. En América Latina el discurso sobre el sistema educativo nacional re-definió el significado de la tarea docente y lo vinculo a una nueva identidad femenina. En los países europeos, la construcción dei sistema educativo nacional excluyó discursiva y materialmente a las mujeres.

En la literatura especializada, se reflejan asimismo dos significados de feminización de las profesiones, que se corresponden con metodologias diferenciales para su tratamiento:

a) Significado cuantitativo (feminilización): en este sentido se refiere ai aumento dei peso relativo dei sexo femenino en la composición de la mano de obra en un determinado tipo de ocupación.

b) Significado cualitativo (feminización propiamente dicha): se refiere a las transformaciones en un determinado tipo de ocupación, originadas a partir de la feminilización y en relación a la imagen de lo femenino predominante en la época, que implican un cambio en el significado de la profesión.

Existe una relación intensa entre el acceso masivo de mano de obra femenina en una determinada profesión (feminilización) y la progresiva transformación cualitativa de la misma (feminización). Con el ingreso 
masivo de mujeres a una profesión, disminuyen las remuneraciones y el trabajo pasa a ser considerado poço calificado. Por otro lado, cuando las profesiones se feminilizan, comienzan a ser concebidas como extensión en el espacio público de la función privada de reproducción social (v.g.: las maestras, las enfermeras, se conciben en relación a la función de "cuidar") (Novaes; 1987 y Louro; 1989). Finalmente, ai considerar el proceso de transformación de una profesión, habria que considerar como se ha producido el cambio y por qué.

^Por qué fue facilmente admitido que las mujeres ingresen por la puerta de la escuela normal a la vida pública? Diversos factores actuaron en este sentido: adernas dei discurso oficial (que fomentaba la incorporación de las mujeres ai sistema educativo nacional como mano de obra barata y disponible), pedagogicamente se creia que las mujeres estaban en mejores condiciones de estimular en los ninos y en las ninas diversas capacidades centrales para la pedagogia científica de la época, que ya no se basaba más en el lema "la letra con sangre entra". Las mujeres "suavizarían" las técnicas pedagógicas, disciplinarían sin castigar. Socialmente, era más fácil admitir que los ninos quedasen en manos de mujeres dentro de la escuela (ai fin y ai cabo, ${ }^{\wedge}$ no eran socializados en las casas por las mujeres?), que admitir que los hombres pasasen a educar a las ninas. Por otro lado, las mujeres en la escuela se encontraban en un espacio público pêro sin demasiados riesgos de "corrupción moral" (Morgade; 1990).

Sintetizando: creemos que la implantación dei proyecto oligárquico y patriarcal en América Latina, estuvo acompanada dei desarrollo de un discurso nuevo, que asignó lugares y roles específicos a las mujeres, porque:

a) debía liberar fuentes de trabajo para los hombres (inmigrantes, exesclavos, criollos que ya no guerreaban, etc), y eliminar la competência femenina era un camino;

b) debía asegurar la constitución y consolidación dei nuevo tipo de família moderna, la família nuclear (censable, cadastrable, controlable, célula básica 
de los modernos estados nacionales); para ello asignaba a las mujeres la función de reproducir (biológica y socialmente) a la fuerza de trabajo, a través de la re-definición de los roles de esposa y madre;

c) debía expandir la educación primaria y esta expansión era muy costosa: edifícios, cuerpo docente, libros, etc; las mujeres resultaban la menor inversión y la más segura: sus salários podían ser menores a los masculinos y permanecían en sus puestos de trabajo por falta de otras oportunidades mejores. Por otro lado, es necesario tener en cuenta que las maestras casadas generalmente trabajaban media jornada, restándoles la otra mitad para desenvolverse como madres y esposas.

En este sentido, la conformación de un cuerpo docente predominantemente femenino se relaciono directamente con la voluntad política, con las políticas públicas implementadas, y con las acciones de ellas derivadas. Indirectamente, se relaciono con la redefinición de las esferas pública, privada y social; con la elaboración de identidades específicas de género, étnicas y nacionales; y con la redefinición dei concepto de maternidad. Todos estos fenómenos, interconectados, crearon un nuevo personaje: "la querida maestra" o la "segunda mama".

\section{Bibliografia $^{10}$}

ALBISETTI, James C. (1988), Schooling German Girls and Women. Secondary and HigherEducation in the Nineteenth Century, Princeton University Press, Princetor

ALLIAUD, Andrea (1989), El maestro como categoria social: génesis y desarrollo Argentina (1880-1915), Universidad de Buenos Aires, Buenos Aires, Junio (mimeo).

ANDERSON, Benedict (1977), Nação e consciência nacional, Atiça, São Paulo, 1989.

El año de edición original figura entre paréntesis. 
APPLE, Michael (1987), "Ensenanza y trabajo femenino: un análisis histórico e ideológico comparado", Revista de Educación, n.283, Mayo/Agosto, p.79-99.

ARAÚJO, Helena C. (1990), "As mulheres professoras e o ensino estatal", Educação e Realidade, Universidad Federal do Rio Grande do Sul, v. 16, n.2,jul./dez., p.45-57.

ARENDT, Hannah (1958), A condição humana, Forense-Universitária, Rio de Janeiro, 1983.

BADINTER, Elisabeth (1980), L 'amour en plus. Histoire de l'amour maternel, Flammarion, Paris.

BENDIX, Reinhard (1964), Nation-Building and Citizenship, University of Califórnia Press.

BERNARDES, Maria T. C. C. (1989), Mulheres de ontem? Rio de Janeiro Século XIX, T. A. Queiroz, São Paulo.

BOURDIEU, Pierre (1989), La noblesse d'état. Grandes Ecoles et esprit de corps, Les Editions de Minuit, Paris.

BREHMER, Use (Hrsg.) (1980), Lehrerinnen. Zur Geschichte eines Frauenberufes. Texte aus dem Lehrerinnenalltag, Urban \& Schwarzenberg, Munchen.

CALDERON, Fernando (Org.) (1988), Imágenes Desconocidas: La modernidad en la encrucijada Post-Moderna, CLACSO, Buenos Aires.

CARMAGNANI, Marcelo (1984), Estadoy sociedad en América Latina (18501930), Grijalbo/Crítica, Barcelona.

COLLIN, Françoise (1986), "Du prive et du public", Les Cahiers du Grif, n.33, Printemps, p.47-68. 
COMTE, Auguste (1830-1842), Cours de Philosophie Positive. Discours sur l'esprit positif, Editions Garnier Frères, Paris, 1934.

COROMINAS, Joan (1954), Diccionario Crítico Etimológico de la Lengua Castellana, Gredos, Madrid.

CORVALAN, Graciela (1990), Mujery Educación en América Latina, Grupo de Estúdios de la Mujer Paraguaya (GEMPA), Asunción (mimco).

DEBESSE, M. et MIALARET, G. (1978), Traité des Sciences Pédagogiques. VII: Fonction et Formation des Enseignants, Presses Universitaires de France, Paris.

DONGHI, Túlio Halperín (1986), Historia contemporânea de América Latina, Alianza, Buenos Aires.

DURKHEIM, Emile (1893), La división dei trabajo social, Akal Editor, 1982.

ENGELBRECHT, H. (1984), Geschichte des òsterreichischen Bildungswesens, Wien.

FELDFEBER, Miriam, Génesis de las representaciones acerca dei maestro. Argentina, 1870-1930, Universidad de Buenos Aires, Instituto de Ciências de Ia Educación, Buenos Aires, Octubre de 1990 (mimco).

FOSTER, Robert (1991), "Making National Cultures in the Global Ecumene", Annual Review ofAnthropology, n.20, p.235-260.

GLAZER, P.M. and SLATER, M. (1986), Unequal Colleagues: the Entrance ofWomen into the Professions, New Brunswick, New Jersey.

HAUSEN, Karin (1976), "Die Polarisierung der 'Geschlechtscharak-tere' — Eine Spiegclung der Dissoziatin von Erwerbs - und Familienleben", in: Conze, W. (Hrsg.), Sozialgeschichte der Familie in derNeuzeit Europas, Emst Klett Verlag, Stuttgart, S. 363-393.

HOBSBAWN, Eric \& RANGER, T. (Ed.) (1983), The invention oftradition, Cambridge University Press, Cambridge. 
ILLICH, Ivan (1982), Le genre vemaculaire, Editions du Seuil, Paris, 1983.

JACOBI, Juliane (1990), "Geistige Mtitterlichkeit", Die deutsche Schule, 1.Beiheft, Weinheim, S. 204-224.

KELLEHER, F.A. (1988), Gender, state policy andprofessionalpolitics: Primary school teachers in France 1880-1920, New York University, New York.

KOVEN, Seth and MICHEL, Sonya (1990), "Womanly Duties: Matemalist Politics and the Origins of Welfare States in France, Germany, Great Britain, and the United States 1880-1920", The American Historical Review, v.95,n.4,p. 1076-1108.

LAROUSSE, P. (1867), Nouveau Dictionnaire Etimologique et Historique, Larousse, Paris, 1971.

LAVRIN, Asunción (Comp.) (1985), Las mujeres latinoamericanas. Perspectivas históricas, Fondo de Cultura Económica, México.

LOURO, Guacira L. (1989), "Magistério de $I^{\circ}$ Grau: um trabalho de mulher", Educação e Realidade, Porto Alegre, v. 14, n.2, jul./dez., p. 31-39.

MARX, Karl (1867), Das Kapital. Khtik der politischen Òkonomie, Erster Band, Dietz Ve Verlag Berlin (MEW 23), 1984.

MORGADE, Graciela (1990), El determinante de género en el trabajo docente de la escuelaprimaria, FLACSO/Programa Argentina, Buenos Aires, Tesis de Maestria, Área Educación y Sociedad.

NOVAES, Maria E. (1987), Professora primária: mestra ou tia, Cortez Editora, São Paulo.

0'BRIEN, George (1970), "Maria Theresa's attempt to educate an Empire", Paedagogica Histórica, v.10, n.3, p.542-565.

RIVAS, E. Torres, "La Nación: problemas teóricos e históricos", en: Lechner, Norbert (ed), Estado y Política en América Latina, Siglo XXI, México, 1986, 4. edición. 
ROSEMBERG, Fulvia et alii (1990), Mulher e educação formal no Brasil: estado da arte e bibliografia, REDUC/INEP, Brasília.

SAMARA, Eni de M. (1989), As mulheres, o poder e a família.

século XIX, Marco Zero/Secretaria de Estado da Cultura de São Paulo.

SCOTT, Joan W. (1983-1988), Gender and the politics ofHistory, Columbia University Press, New York, 1988.

SHORTER, Edward (1975), Naissance de la famille moderne, Seuil, Paris, 1977.

SIMMEL, Georg (1911), Sobre la aventura. Ensayos filosóficos, Ediciones Península, Barcelona, 1988.

STODOLSKY, C. E. (1987), Missionary of the feminine mystique: the female teacher in Prússia aa and Bavaria: 1880-1920, State University of New

URBAN, Wayne (1990), "Historical Studies on Teacher Education", in: Houston, R. (Ed.) (1990), Handbook of Research on Teacher Education, MacMillan Publishing Company, New York/London, p.59-71.

WAINERMANN, Catalina y NAVARRO-ARANGUREN, Marysa, El trabajo de la mujer en la Argentina: un análisis preliminar de las ideas dominantes en lasprimeras décadas dei siglo XX, CENEP, Buenos Aires, 1979, mimeo.

WEINBERG, Gregório (1984), Modelos educativos en la historia de América Latina, Kapelusz, Buenos Aires.

WILKING, Susanne (1990), "Die Berufsausbildung der Volksschullehrerinnen und Volksschullehrer in Italien von 1860 bis 1900", Paedagogica Histórica. InternationalJournal ofthe History of Education, XXVI, 3, Gent, S. 47-

WILLIAMS, Brackette (1989), "A class act. Anthropology and the race to nation across ethnic terrain", Annual Review of Anthropology, n.18, p.401444. 
ZEA, Leopoldo (1949), Dos etapas dei pensamiento en Hispanoamérica. Del romanticismo ai positivismo, El Colégio de México, México.

ZEA, Leopoldo (1986), América Latina en sus ideas, Siglo XXI, México.

Recebido em 14 de Janeiro de 1994.

Silvia Cristina Yannoulas, mestre em Ciências Sociais pela Facultad Latinoamericana de Ciências Sociales (FLACSO)/Programa Argentina, é doutoranda em Sociologia pelo Programa de Doutoramento Conjunto FLACSO/UnB em Estudos Comparativos sobre a América Latina e o Caribe.

This paper analyses the process of teaching force's feminizailion, in Latin-America (1870-1930). We discuss the relationship between the feminizaiion of íhis profession, íhe building and expansion ofnaíional educaíion systems, and îhe elaboraíion and diffusion of differeni kinds ofidenfiíy (especially gender and naíional ideníiiies). This ariicle is organized around "Key-words", so as: sexual difference, sexual division of labor, public andprivaíe, educaíor Slaie, feminine educaíion, ieaching profession, ieacher 's educaíion and feminizaíion ofíhe ieaching profession.

Ceí aríicle se propose de coniribuer avec ceríains apporís lheóriques aux débais sur le procès de féminisaiion de la profession enseignanie dans l'école primaire des pays lalino-américains entre 1870 et 1930. On discuíe les relalions eníre la féminisaiion du corps enseignaní, la consíiiuíion eí expansion des sysièmes de l'educaíion naíionale eíl 'elaboraíion eí diffusion de différeníes ideníités (en particulier des identiiés de genre 
et de nationalite). Le texte est organisé autourde "mots-clef" direcíement lies à la problématique de la féminisaíion, ieis que différence sexuelle, división sexuelle du íravail, public et prive, État enseignaní, éducaíion féminine, profession enseignante, formation des maiires eí féminisaíion du corps enseignaní.

Esíe artículo tiene por objeíivo aporlar elemenios íeóricos ai debaíe sobre el proceso de feminización de la docência en la escuela primaria, en el coníexío laíinoamericano, eníre los anos 1870 y 1930. Discuíe la relación eníre la feminización de la docência, la consííución y expansión de los sistemas educativos nacionales, y la elaboración de distinío ípo de identidades (paríicularmenie identidades de géneroy nacionales). Se organiza alrededor de "palabras-clave" (key-words), vinculadas a la problemática de la feminización: diferencia sexual, división sexual dei trabajo, público y privado, Estado educador, educación femenina, profesión docenie, formación doceníe y feminización de la docência. 